\title{
BIOSKOP DI MALs KONSUMSI DAN KOMODIFIKASI dalam BUdaya URBAN
}

\section{MOVIE THEATER IN SHOPPING MALLS: CONSUMPTION AND COMMODIFICATION IN URBAN CULTURE}

\author{
Gorivana Ageza, Aquarini Priyatna, R.M. Mulyadi \\ Program Studi Magister Kajian Budaya, Fakultas Ilmu Budaya, \\ Universitas Padjajaran \\ e-mail: gorivana.ageza@gmail.com, aquarini@unpad.ac.id, luckysejarawan@gmail.com
}

\begin{abstract}
Abstrak
Di Kota Bandung, hampir semua mal memiliki bioskop, dan sebaliknya, tidak ada bioskop di luar mal. Artikel ini akan memaparkan konsekuensi dari keberadaan bioskop di mal. Artikel ini disusun berdasarkan observasi lapangan dan studi pustaka, yang kemudian ditafsirkan secara hermeneutika dengan pendekatan teori kritis. Observasi lapangan dilakukan di dua bioskop terbesar di Kota Bandung yakni CGV Cinemas Mal Paris van Java dan Ciwalk XXI Mal Cihampelas Walk. Fenomena bioskop di mal menunjukkan bahwa kehidupan urban menyebabkan komodifikasi ruang dan pengalaman. Berbelanja di mal dan menonton film di bioskop mal mengarahkan warga urban untuk melakukan konsumsi, serta memaksimalkan keuntungan yang didapat oleh mal dan bioskop.
\end{abstract}

Kata kunci: mal, bioskop, penonton, ruang, pengalaman.

\begin{abstract}
In Bandung city, virtually all shopping malls list movie theaters among their venue. Conversely, there is no movie theater located out of shopping mall. This article explains consequences of movie theater in shopping malls. This article is written based on field observation and literature study, which then was interpreted hermeneutically, using critical theory approach. Field observations were conducted at two biggest movie theaters in Bandung's shopping malls, which are CGV Cinemas in Paris van Java Mall and Ciwalk XXI in Cihampelas Walk Mall. This phenomenon indicates that urban life causes commodification on space and experience. Both the act of shopping and watching movies in shopping malls lead urban people to a consumptive lifestyle while maximizing the revenues of both shopping malls and movie theaters.
\end{abstract}

Keywords: shopping mall, movie theater, audience, space, experience.

\section{A. PENDAHULUAN}

Tutupnya Regent 21 dan Astor secara berturut-turut pada rentang tahun 2011-2013 menandai bahwa di Kota Bandung tidak ada lagi bioskop yang berbentuk bangunan mandiri (Adi, 2013; Maradona, 2011). Akibatnya, sejak saat itu bioskop hanya berada di mal (pusat perbelanjaan). Hingga awal April tahun 2018, di Bandung terdapat lima belas bioskop di mal yakni Ciwalk XXI di Mal Cihampelas Walk, CGV Cinemas Paris van Java di Mal Paris van Java, Cinemaxx Istana Plaza di Mal Istana Plaza, BTC XXI di Mal Bandung Trade Center, Empire BIP XXI di Mal Bandung Indah Plaza, CGV Cinemas Paskal23 di Mal Paskal23, Braga XXI di Mal Braga Citywalk, TSM XXI di Trans Studio Mall, CGV Cinemas BEC di Mal Bandung Electronic Center, Feslink 
XXI di Mal Festival Citylink, CGV Cinemas Miko di Milan Kopo Mall (Miko Mall), CGV Cinemas Metro Indah Mall di Metro Indah Mall, Transmart Buah Batu XXI di Mal Transmart, Ubertos XXI di Mal Ujung Berung Town Square, dan Jatos 21 di Mal Jatinangor Town Square ${ }^{1}$. Kelima belas bioskop tersebut menunjukkan dua hal. Pertama, nama bioskop diambil dari nama mal yang ditambahkan dengan merek jaringan bioskop. Kedua, nyaris semua mal di Bandung memiliki bioskop. Fenomena tersebut kemudian menimbulkan pertanyaan: Bagaimana relasi antara mal dan bioskop, serta apa konsekuensi dari penyatuan keduanya?

Sejak tahun 1986, terjadi perubahan konsep bioskop yang dipelopori jaringan bioskop Cineplex 21 (Sen, 2009: 107). Pada mulanya bioskop berbentuk bangunan mandiri dan hanya terdiri atas sebuah ruangan untuk menonton (studio/teater/auditorium) berukuran besar yang dapat menampung ratusan penonton. Sementara itu, bioskop dengan bentuk baru memiliki format sinepleks (kompleks sinema), yakni sebuah bioskop yang terdiri atas beberapa ruangan untuk menonton (studio/teater/auditorium). Sebuah bioskop, dengan demikian, memiliki sejumlah variasi film dan tipe studio/teater/auditorium yang dapat dipilih oleh calon penonton. Sebagai catatan, jaringan bioskop Cineplex 21 juga menjadi pelopor konsep bioskop berjaringan di Indonesia.

Bersinggungan dengan konsep sinepleks, terjadi pula perubahan lain yakni integrasi antara bioskop dengan pusat perbelanjaan. Masuknya bioskop sinepleks ke dalam bangunan pusat perbelanjaan

1 Bioskop Jatos 21 terletak pada pusat perbelanjaan Jatinangor Town Square yang terletak di area perbatasan antara Bandung dan Sumedang. Secara administratif Jatinangor termasuk pada area Kabupaten Sumedang, namun pada laman internet situs resmi Cineplex 21 (www.21cineplex.com), Jatos 21 dikategorikan pada area Bandung. awalnya dimungkinkan karena kepemilikan yang sama antara jaringan bioskop Cineplex 21 dengan jaringan pasar swalayan Golden Truly (Sen, 2009: 108). Seiring perkembangan zaman, keberadaan bioskop-bioskop dalam bentuk bangunan mandiri dan kepemilikan mandiri (di luar jaringan bioskop Cineplex 21) mulai tutup. Kondisi tersebut diperparah oleh situasi perfilman tanah air yang terpuruk pada era tahun 1990-an. Bioskop jaringan dengan format sinepleks diuntungkan karena afiliasinya dengan pasar swalayan, pemutaran film-film impor, serta fasilitas bioskop yang nyaman dan mutakhir (Sen, 2009: 107). Saat ini di Indonesia, kita mengenal jaringan-jaringan bioskop lain, seperti CGV Cinemas dan Cinemaxx, sebagai kompetitor dari jaringan bioskop Cineplex 21. Saat ini baik bioskop jaringan maupun bioskop non-jaringan memilih bergabung dengan mal, dan ini merupakan fenomena yang akan didedah lebih lanjut dalam artikel ini.

Keberadaan mal sendiri adalah salah satu penanda kehidupan urban atau kota modern. Walter Benjamin menegaskan ide tersebut dengan ungkapan "... an arcade is a city, a world of miniature" (Buck-morss, 1989). Arcade adalah bentuk pusat perbelanjaan di abad 20, berupa lorong/gang dengan deretan toko di sepanjang kiri-kanannya. Dengan perkataan lain, mal adalah miniatur dari kota urban. Sementara itu, Karl Marx dan Friedrich Engels sebagaimana dikutip oleh Simon Parker mengatakan bahwa kapitalisme yang menciptakan kota modern, dan bukan sebaliknya (2004). Kedua premis tersebut mengisyaratkan bahwa arcade atau mal adalah pengejawantahan dari sistem kapitalisme.

Berdasarkan penelusuran kami, di Indonesia belum ada penelitian atau artikel yang menelaah fenomena bioskop di mal. Sementara dari luar Indonesia, terdapat dua artikel yang berkelindan dengan artikel Bioskop di Mal: Konsumsi dan Komodifikasi dalam Budaya Urban. Pertama, tulisan dari William Paul yang 
bertajuk The K-Mart Audience at the Mall Movies dimuat dalam jurnal Film History vol. 6, no. 4 (1994). Tulisan The K-Mart Audience at the Mall Movies meneliti sejarah sinema dunia yakni bagaimana bioskop yang mulanya berupa bangunan mandiri dan hanya terdiri atas sebuah ruang pemutaran (studio/teater/auditorium) kemudian berubah menjadi kompleks sinema (sinepleks) yang terdiri atas beberapa ruang pemutaran (studio/teater/auditorium), serta berada di pusat perbelanjaan. Industri perfilman Hollywood dan dinamika sosial di Amerika Serikat menjadi faktor yang memelopori perubahan format bioskop di dunia. Kedua, tulisan berjudul Les Flaneurs du Mal(l): Cinema and the Postmodern Condition yang merupakan salah satu bab dalam Window Shopping: Cinema and Postmodernism karya Anne Friedberg (1993). Friedberg (1991: 423) memaparkan bahwa layar bioskop analog dengan jendela pajang pada toko-toko di mal. Mal adalah konsekuensi logis dari keberadaan bioskop (Friedberg, 1991: 425). Friedberg (1991: 424) menggarisbawahi fenomena tersebut dengan ungkapan "the mall is a theatre".

Artikel ini akan menunjukkan konsekuensi dari keberadaan bioskop di mal. Sebagai catatan, artikel ini menggunakan pendekatan teori kritis. Teori kritis adalah corak pemikiran yang diinisiasi oleh para pemikir dari Mazhab Frankfurt. Mazhab Frankfurt adalah sebuah lembaga penelitian yang didirikan di Frankfurt, Jerman, pada tahun 1923 (Barker, 2014: 53). Beberapa pemikir utama dari Mazhab Frankfurt adalah Theodore Adorno, Max Horkheimer, dan Herbert Marcuse (Barker, 2014: 53).

Mazhab Frankfurt menggunakan pendekatan interdisipliner, antara lain marxisme, filsafat kritis, dan psikoanalisis, untuk mengkritik kapitalisme, khususnya industri budaya (Barker, 2014: 53). Mazhab Frankfurt mengembangkan tradisi filsafat Jerman yakni kritik yang berupaya untuk memperbaiki, sekaligus juga mempertahankan hal-hal yang bernilai (Barker, 2014: 53). Saat ini teori kritis tidak lagi hanya identik dengan Mazhab Frankfurt, melainkan menjadi terminologi yang dipakai secara luas, yakni sebagai analisis tekstual dan budaya yang didasarkan pada pemikiran kunci dari Teori Kritis Mazhab Frankfurt (Barker, 2014: 54).

\section{B. METODE PENELITIAN}

Artikel ini disusun dengan metode studi kepustakaan dan observasi lapangan. Analisis dalam artikel ini menggunakan hermeneutika. Hermeneutika adalah ilmu menafsir makna (Maulana, 2002: 43). Terminologi hermeneutika berasal dari bahasa Yunani, hermeneuin yang berarti menafsir. Pada mulanya hermeneutika digunakan untuk menafsir teks kitab suci, namun pada perkembangannya hermeneutika akhirnya digunakan untuk menafsirkan segala jenis "teks", termasuk realitas hidup keseharian (Maulana, 2002: 49).

Tesis ini akan mengaplikasikan Hermeneutika versi Hans-Georg Gadamer. Dalam hermeneutika versi Hans Georg Gadamer, dikotomi rigid antara subjek dan objek tidak ada lagi: subjek mempengaruhi objek, dan objek mempengaruhi subjek (Maulana, 2002: 49). Dalam melakukan penafsiran, objektivitas tidak dapat dicapai sebab setiap penafsir memiliki pengalaman dan kerangka pikiran yang berbeda dalam memahami suatu realitas (Maulana, 2002: 49). Gadamer menyebutkan istilah "lingkaran hermeneutis" untuk menjelaskan teorinya (Maulana, 2002: 49). Terjadi interaksi dua arah, atau dengan kata lain, terjadi dialog yang memperkaya pemikiran. Dengan demikian, tercipta suatu makna baru yang disebut Gadamer dengan istilah peleburan/fusi horizon. Hermeneutika Gadamer menuntut adanya koherensi antara keseluruhan teks dengan bagian-bagiannya (Wattimena, 2009). Proses pemaknaan atas sesuatu merupakan proses yang berlangsung tiada akhir (Wattimena, 2009). 
Kajian budaya dipengaruhi oleh hermeneutika dalam perkara kebebasan bagi pembaca "teks" dalam menyusun penafsiran (Barker, 2014: 121). Penafsiran dari pembaca terlepas dan dibebaskan dari intensi pembuat "teks" (Barker, 2014: 121). Penafsiran terhadap "teks" tidak dapat dan tidak perlu dilepaskan dari posisi dan sudut pandang penafsir (Barker, 2014: 122). Dengan perkataan lain, tidak ada makna tunggal dan absolut. Hermeneutika memungkinkan terciptanya reproduksi makna dan penciptaan makna baru (Barker, 2014: 122).

Metode hermeneutika dipilih karena memungkinkan peleburan antara kami sebagai peneliti dengan fenomena yang diamati yakni mal dan bioskop. Di satu pihak, kami mengalami dan menghidupi kedirian sebagai manusia urban yang mengunjungi mal dan menonton film pada pada bioskop di mal. Di saat bersamaan, kami mengambil jarak dari lokus kehidupan keseharian tersebut agar dapat memahami kehidupan urban dengan refleksi kritis dan objektif.

Objek penelitian dari artikel ini adalah dua bioskop terbesar di Kota Bandung, yakni CGV Cinemas Paris van Java dan Ciwalk XXI. CGV Cinemas Paris van Java berada di mal Paris van Java. Ciwalk XXI berada di mal Cihampelas Walk (Ciwalk).

Pembahasan artikel ini akan terbagi menjadi empat bagian. Pertama, pembahasan mengenai bioskop CGV Cinemas Paris van Java dan Ciwalk XXI. Kedua, pembahasan mengenai bagaimana bioskop di mal mengomodifikasi ruang. Ketiga, pembahasan mengenai bagaimana bioskop di mal mengubah dan mengomodifikasi pengalaman hidup manusia urban. Bagian terakhir akan membahas bagaimana korelasi antara komodifikasi ruang dan pengalaman, serta konsekuensi keduanya.

\section{HASIL DAN BAHASAN}

Terdapat keserupaan antara CGV Cinemas Paris van Java dengan Ciwalk XXI meskipun keduanya berada di pusat perbelanjaan yang berbeda, serta terafiliasi dengan jaringan bioskop yang berbeda pula. Kondisi dan gejala yang nampak dari kedua bioskop tersebut, sekaligus pula menunjukkan kondisi dan gejala yang terjadi secara general pada fenomena bioskop di mal.

\section{Bioskop CGV Cinemas Paris van Java di mal Paris van Java dan Ciwalk XXI di mal Cihampelas Walk}

Cihampelas Walk atau yang disingkat menjadi Ciwalk adalah mal yang berdiri pada tahun 2004, dan berlokasi di Jalan Cihampelas 160. Sementara Paris van Java adalah mal yang berdiri pada tahun 2006, dan berlokasi di Jalan Sukajadi 131-139. Kedua mal tersebut memiliki beberapa kemiripan. Pertama, keduanya memiliki gaya bangunan yang menyerupai arcade (pusat perbelanjaan awal abad 20), yakni berupa lorong panjang dengan deretan toko-toko di kirikanannya. Kedua, kedua mal tersebut mempunyai konsep bangunan hijau (green building) yang ditunjukkan dengan keberadaan taman dan area terbuka hijau. Ketiga, kedua mal tersebut memiliki bioskop terbesar di Bandung. Keempat, kedua bioskop tersebut terletak di lantai teratas dan/atau berada di area pojok dari bangunan mal.

Sebelum diakusisi oleh perusahaan multinasional Korea Selatan, dahulu CGV Cinemas bernama Blitz Megaplex (Bookmyshow, 2017a). Blitz Megaplex yang terletak di mal Paris van Java berdiri pada tahun 2006, dan merupakan bioskop pertama di Indonesia milik jaringan Blitz Megaplex. CGV Cinema Paris van Java merupakan bioskop terbesar di Bandung dengan keberadaan sebelas auditorium yang meliputi delapan auditorium regular, sebuah auditorium 4DX, dan dua auditorium Velvet Class. Sebagai catatan, $\mathrm{CGV}$ Cinemas menggunakan istilah 
auditorium untuk menyebut ruangan menonton. Velvet Class adalah auditorium yang memungkinkan penonton menyaksikan film dari atas ranjang yang dilengkapi dengan selimut, dan bukannya kursi seperti umumnya ruangan bioskop. Penonton dari auditorium Velvet Class dapat memanggil pegawai CGV Cinemas melalui bel untuk memesan makanan atau minuman. Sementara 4DX adalah auditorium yang memungkinkan penonton mengalami sensasi empat dimensi dari tayangan yang ditontonnya, seperti kemunculan angin, cahaya yang menyerupai kilat, air, serta kursi penonton yang dapat bergerak. CGV Cinemas Paris van Java juga dilengkapi dengan keberadaan toko roti dan kafe Tous les Jours, serta ruang tunggu eksekutif.

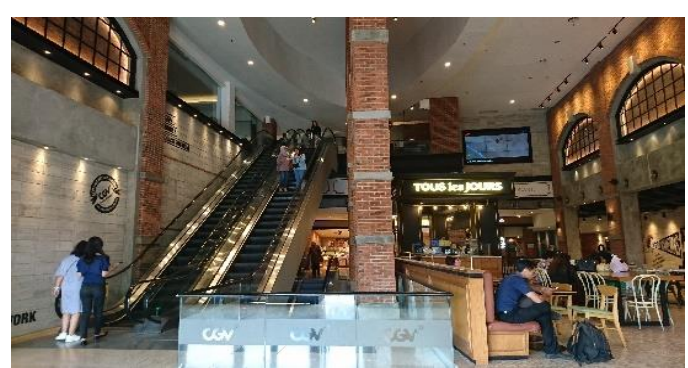

Gambar 1. Suasana CGV Cinemas di Mal Paris van Java

Sumber: Ageza, 2018.

Cineplex 21 didirikan pada tahun 1986, dan menguasai industri bioskop nasional selama lebih dari tiga dekade. Grup Cineplex 21 memiliki empat merek dagang yakni Cinema 21, Cinema XXI, The Premiere, dan IMAX (Bookmyshow, 2017b). Hingga April 2018, Cinema 21 sudah memiliki 989 layar bioskop yang tersebar di 176 lokasi yang tersebar pada 41 kota di Indonesia (Cineplex21, 2018b).

Bioskop Ciwalk XXI terdiri atas 10 studio, yakni 8 studio regular dan 2 studio The Premiere. Sebagai catatan, Cineplex 21 menggunakan istilah studio untuk menyebut ruangan menonton. The Premiere adalah studio yang menawarkan fasilitas lebih mewah ketimbang studio regular. Fasilitas yang disediakan The
Premiere antara lain, loket tiket dan kafe yang terpisah dari penonton regular, tempat duduk penonton berupa sofa yang sandaran tubuh dan kakinya dapat diatur, serta ketersediaan meja dan selimut. Jumlah kursi dalam sebuah studio The Premiere juga lebih sedikit ketimbang studio regular. Serupa dengan CGV Cinemas Paris van Java, Ciwalk XXI juga dilengkapi dengan kafe dan ruang tunggu eksekutif.

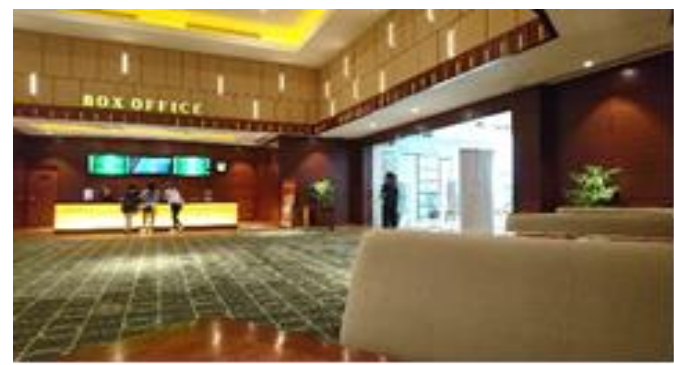

Gambar 2. Suasana Ciwalk XXI di Mal Cihampelas Walk

Sumber: Ageza, 2018.

CGV Cinemas dan Cineplex 21 menampilkan citra bioskop yang relatif berbeda. CGV Cinemas menampilkan bioskop sebagai tempat untuk mendapatkan pengalaman dan ruang bermain. Hal tersebut tercermin dari ketiadaan batas yang tegas antara area bioskop dengan area mal (lapak/toko lainnya), sehingga memberikan kesan dinamis. Tata ruang CGV Cinemas merupakan kombinasi dari gaya bioskop Amerika klasik (lampu-lampu bohlam, ornamen retro seperti mural Marilyn Monroe), dan gaya industrial (dengan dinding bata, pipa, dominasi warna hitam dan warna natural). Para pegawai CGV Cinemas menegaskan citra tersebut dengan seragam yang mereka kenakan yakni berupa jumpsuit bergaya pekerja industri atau montir. Citra bermain ditegaskan juga oleh mural yang ditampilkan di dinding CGV Cinemas Paris van Java "Play at $C G V$ ”. Untuk membedakan diri dari jaringan bioskop lain, dinding CGV Cinemas menampilkan mural bertuliskan 
"We're Unique in Everyway" dan "Cut Away the Old Framework".

Berbeda dari CGV Cinemas, Cineplex 21 menampilkan citra bioskop yang elegan dan eksklusif. Citra eksklusif tercermin dari keberadaan dinding dan pintu kaca yang membatasi area mal dengan area bioskop. Sementara kesan elegan tercermin dari lantai marmer, karpet, serta pencahayaan dan ornamen ruangan yang menggunakan warna hangat seperti krem dan coklat. Citra tersebut ditegaskan pula dengan seragam pekerja Cineplex 21 yang berwarna hitam bergaya elegan, menyerupai seragam pramugari. Pekerja perempuan Cineplex 21, baik yang bertugas di area tiket, penjaga di studio, hingga petugas kebersihan diwajibkan menggulung rambutnya.

Sebagaimana kekhasan jaringan Cineplex 21, bioskop Ciwalk XXI menawarkan variasi film Indonesia dan Hollywood kepada calon penonton. Cineplex 21 juga memutarkan film Hongkong, namun dalam jumlah minim. Misalnya, pada akhir bulan Januari 2018, Ciwalk XXI memutarkan film Hongkong Bleeding Steel yang dibintangi oleh Jackie Chan. Sementara itu, CGV Cinemas memiliki variasi tawaran film yang lebih luas di samping film Indonesia dan film Hollywood, seperti film Thailand, film Korea Selatan, film Jepang, dan animasi Jepang. CGV Cinemas Paris van Java dan Ciwalk XXI juga memilliki kesamaan film yang ditawarkan. Misalnya, pada pekan pertama Februari 2018 film Dilan 1990 dan Maze Runner menjadi dua film yang tidak hanya mendominasi CGV Cinemas Paris van Java dan Ciwalk XXI, melainkan juga tiap-tiap bioskop di Kota Bandung. Film Dilan 1990 bahkan diputar di tiga auditorium CGV Cinemas Paris van Java (CGVCinemas, 2018b).

Aspek promosi dan jadwal pemutaran bioskop menjadi faktor penting untuk mempertemukan antara film dan penonton. Neon box dan layar datar LED yang berada di area bioskop mal menampilkan jadwal pemutaran dan poster-poster film yang tengah atau akan diputarkan. Sementara itu, jadwal pemutaran dan promosi film yang ditujukan kepada publik dilakukan melalui iklan pada media cetak (umumnya di surat kabar), media elektronik, dan media sosial. Selain itu terdapat pula situs resmi bioskop yang dapat diakses oleh publik. Situs resmi Cineplex 21 (2018a) dan CGV Cinemas (2018a) menampilkan tidak hanya promosi film dan jadwal pemutaran bioskop, melainkan juga memungkinkan penonton untuk membeli tiket dan memilih tempat duduk secara daring.

Salah satu faktor signifikan dari keberadaan bioskop adalah teknologi. Penguasaan terhadap teknologi menjadi pembeda antarbioskop, sekaligus pula menjadi keunggulan yang dijual masingmasing bioskop kepada calon penonton. Teknologi mengacu pada fasilitas yang terdapat pada ruangan menonton film (studio/teater/auditorium) dan pada keseluruhan area bioskop. Contoh fasilitas dalam ruangan menonton adalah teknologi suara Dolby Atmos. Pada Ciwalk XXI, penggunaan teknologi di toilet mengejawantah pada keberadaan keran dan dispenser sabun dengan sensor otomatis. Pada CGV Cinemas Paris van Java, ekspos pada teknologi tercermin dari keberadaan mesin-mesin tiket swalayan (selfticketing), layar-layar datar LED penampil menu makanan minuman, serta layar besar (megatron) yang menampilkan cuplikan film terbaru. Di Ciwalk XXI terdapat pula fasilitas khusus yang tidak dapat ditemui di CGV Cinemas Paris van Java, yakni arena videogame yang disebut XXI Games. Selain teknologi yang berada pada area bioskop, bioskop juga didukung oleh terknologi informasi yang menghubungkan pihak bioskop dengan calon penonton di luar area mal. Misalnya, laman situs resmi bioskop memungkinkan penonton melihat jadwal pemutaran film melalui, dan melakukan pemesanan tiket secara daring.

Teknologi juga merupakan faktor signifikan dalam keberlangsungan mal. Misalnya pada sistem parkir, 
eskalator/travelator/lift, sistem keamanan (kamera pengawas, alarm peringatan bahaya, alat sensor, dsb), dan sistem transaksi keuangan (sistem barcode, mesin kasir, ATM, mesin debet/kredit, dsb). Dapat dikatakan bahwa produk teknologi adalah komoditas yang dijual di mal.

Meski mal sendiri memiliki berbagai fasilitas dan tawaran produk, bioskop di mal menyediakan fasilitas mandiri yang khusus diperuntukkan bagi penontonnya, seperti toilet, kafe/restoran, serta lapak yang menjual makanan dan minuman ringan seperti brondong jagung dan minuman bersoda. Oleh karena itu, makanan/minuman yang dibeli dari lapak lain di mal tidak diperkenankan untuk dibawa ke dalam ruangan menonton (studio/teater/auditorium). Produk makanan dan minuman yang ditawarkan pihak bioskop cenderung dibandrol dengan harga yang lebih mahal ketimbang produk sejenis yang dijual oleh lapak lain di mal (Halim, 2017).

Pada kedua bioskop, makanan yang ditawarkan mengakomodasi cita rasa global, antara hotdog, hamburger, kentang goreng, dan minuman soda. Untuk memberikan variasi dari standar global, ditambahkan menu-menu lokal. Sebagai catatan, umumnya menu lokal tetap ditampilkan dalam bahasa Inggris. Sebagai contoh, CGV Cinemas Paris van Java menyediakan menu kudapan pisang goreng dan risoles.

Tidak hanya kafe, restoran, dan toilet yang terpisah dari pengelolaan mal, bioskop juga memiliki petugas kebersihan dan keamanan tersendiri yang berbeda dari petugas kebersihan dan keamanan mal. Upaya memelihara keamanan tercermin dari keberadaan kamera pengawas di dalam dan luar studio/teater/auditorium, serta petugas keamanan. Umumnya toko dan lapak di mal tidak memiliki petugas keamanan pribadi. Sebagai contoh, bioskop-bioskop di bawah jaringan Cineplex 21 mengeksplisitkan prinsip keamanan ini dengan keberadaan pintu kaca sebagai akses masuk, dan petugas keamanan yang dilengkapi dengan alat detektor logam. Keberadaan pintu kaca tidak hanya memisahkan area mal dengan bioskop, melainkan juga mengontrol arus keluar masuk calon penonton, sehingga lebih mudah diawasi dan diperiksa oleh petugas keamanan. Kondisi yang umum terjadi adalah petugas keamanan meminta penonton yang membawa makanan dan minuman dari luar bioskop untuk menitipkan makanan dan minumannya di loker sebelum memasuki area bioskop.

Sebagaimana yang sudah disinggung sebelumnya, konsep bangunan hijau yang ditampilkan oleh Mal Ciwalk dan Mal Paris van Java juga merangsek ke dalam area bioskop. Pada area Ciwalk XXI ditempatkan tanaman-tanaman hidup di seputar area bioskop. Pada area tunggu terdapat jendela kaca berukuran besar yang memungkinkan pengunjung melihat pemandangan hijau di belakang gedung Mal Cihampelas Walk. Kafe The Premiere Ciwalk XXI memberikan pilihan tempat duduk dalam ruangan (indoor) atau di luar ruangan (outdoor) kepada konsumennya.

CGV Cinemas Paris van Java memiliki kondisi serupa. Pada lantai pertama area CGV Cinemas Paris van Java terdapat pintu kaca yang terhubung dengan area hijau dan area parkir. Sementara pada lantai kedua, tepatnya pada lorong yang menghubungkan auditorium regular dengan Velvet Class, terdapat kandang burung dan kandang ayam.

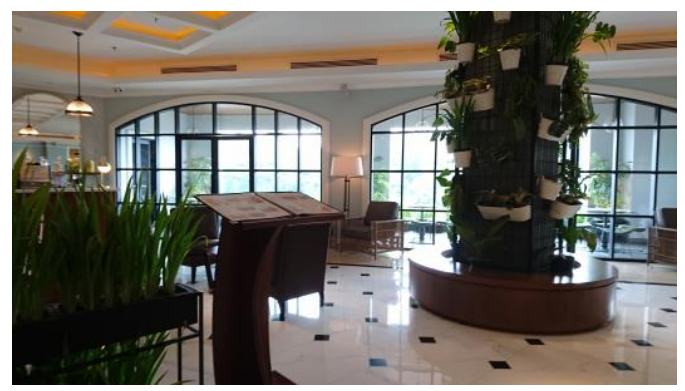

Gambar 3. Tanaman hijau dan suasana area kafe The Premiere Ciwalk XXI di Mal Cihampelas Walk. Sumber: Ageza, 2018. 


\section{Komodifikasi Ruang}

Modernitas telah mengubah cara manusia memahami ruang dan waktu (Redana, 2016). Dalam pemahaman baru, waktu dimaknai menjadi sesuatu yang objektif dan mekanis. Sementara itu, ruang manusia untuk hidup bersama, diprivatisasi. Georg Simmel, seperti diterangkan Parker (Parker, 2004), menegaskan bahwa kota dan ketepatan waktu adalah hal yang tidak dapat dipisahkan. Mekanisasi waktu tercermin dalam berbagai pengaturan waktu, salah satunya adalah jadwal pemutaran film di bioskop.

Privatisasi ruang hidup manusia menyebabkan kelangkaan atas ruang publik. Kondisi tersebut kemudian dimanfaatkan oleh keberadaan mal. Mal menjadi pseudo ruang publik: seolah-olah adalah ruang publik. Sementara itu, Friedberg (1991: 424) menyatakan bahwa mal adalah tempat untuk menunda realitas urban, dan memblokir kerusakan urban seperti kejahatan, kemacetan, perubahan cuaca, dan kaum marjinal. Mal juga menghadirkan ilusi akan keamanan, kebersihan, dan kenyamanan (Friedberg, 1991: 424). Ruang yang ditawarkan oleh mal perlu dikompensasi dengan alat tukar objektif yakni uang.

Dalam The K-Mart Audience at Mall Movies, Paul (1994: 493) memaparkan bahwa masuknya bioskop ke dalam bangunan mal menguntungkan kedua belah pihak. Pihak bioskop diuntungkan karena dua hal. Pertama, karena bioskop tidak lagi berupa bangunan mandiri, ia tidak perlu diberatkan dengan biaya properti yang semakin lama semakin tinggi. Kedua, bioskop memiliki keleluasaan untuk menyewa lantai teratas dari bangunan mal. Di lain pihak, mal diuntungkan karena iklan film yang umumnya memiliki jangkauan secara nasional secara tidak langsung mengiklankan mal. Berdasarkan observasi lapangan yang kami lakukan, pemikiran Paul tersebut dieksplisitkan dengan penamaan bioskop yang memuat nama mal. Dengan perkataan lain, penyatuan mal dan bioskop dapat memperkecil modal dan biaya operasional yang dikeluarkan, serta memberikan keuntungan kepada masing-masing pihak.

Selain hal yang dipaparkan oleh William Paul (1994), integrasi bioskop ke dalam bangunan mal berkaitan dengan paradigma masyarakat urban mengenai ruang dan waktu yakni pemampatan ruang. Paradigma tersebut memungkinkan ruang berukuran terbatas memiliki fungsi yang maksimal. Mal adalah sebuah ruang yang memiliki banyak elemen dan fungsi.

Terdapat faktor pendukung keberadaan mal, antara lain prinsip efektivitas dan efisiensi, serta kemacetan yang umum terjadi di daerah urban. Pemampatan ruang memberikan keuntungan lain, yakni penghematan waktu. Keberadaan mal dan konsep one stop shopping memungkinkan warga urban menghemat waktu dan uang dengan tidak perlu berpindah antartempat. Kondisi tersebut berbanding terbalik dengan konsep bioskop masa lampau berupa bangunan mandiri. Dengan keberadaan bioskop di mal, pengunjung mal tidak hanya dapat menonton film, melainkan juga dapat sekaligus memenuhi kebutuhan lainnya. Prinsip integrasi diterapkan pula pada lapak lain di mal, misalnya pasar swalayan. Istilah toko serba ada (toserba) yang mengacu pada pasar swalayan menunjukkan bagaimana konsumen dapat membeli berbagai macam kebutuhan sehari-hari tanpa harus keluar dari area pasar swalayan.

Integrasi yang dilakukan mal, secara tidak langsung telah menciptakan ruang kondusif bagi terciptanya co-opetition (cooperative competition) antartoko/lapak di mal. Co-opetition adalah neologisme yang mengacu pada kondisi ketika kompetisi justru saling menguntungkan masing-masing pihak. Prinsip co-opetition dipaparkan dalam buku Theory of Games and Economic Behaviour karya John von Neumann dan Oskar Morgenstern (2004). Sebagaimana kompetisi yang terjadi di antara berbagai toko dan lapak yang berada 
di mal, kompetisi juga terjadi di bioskop. Pertama, bioskop berkompetisi dengan toko/lapak lain yang berada di mal. Kedua, film-film yang diputarkan di suatu bioskop saling bersaing satu sama lain untuk mendapatkan penonton. Kondisi ini tercermin dari keberadaan neon box yang menampilkan poster, dan layar yang memutarkan trailer dari film-film yang ditawarkan oleh pihak bioskop kepada calon penonton. Dengan perkataan lain, jika film adalah produk, maka bioskop adalah etalase atau jendela pajangnya. Pada contoh kasus kompetisi antara film Dilan 1990 dan Maze Runner tercermin pula hal lain, yakni kompetisi global: produk lokal bersaing dengan produk impor. Kompetisi produk lokal dan impor/multinasional terjadi pula di berbagai toko/lapak lain di dalam mal. Ketiga, kompetisi antarmal. Keempat, kompetisi antarbioskop, khususnya bagi bioskop yang terafiliasi dengan jaringan yang berbeda. Cineplex 21 dan CGV Cinemas menjadi contoh konkret kompetisi global. CGV Cinemas dimiliki oleh CJ CGV, perusahaan asal Korea Selatan. Sementara Cineplex 21 yang selama 30 tahun merupakan perusahaan lokal, terhitung sejak 2016 membagi kepemilikan sahamnya dengan perusahaan asal Singapura (Kompas, 2016).

CGV Cinemas Paris van Java, Ciwalk XXI, dan bioskop-bioskop lain selalu terletak di lantai teratas dan area pojok dari bangunan mal. Paul (1994: 493) menjelaskan fenomena ini dengan mengatakan bahwa bioskop membutuhkan tempat yang tersembunyi agar memberikan kesan misterius dan menimbulkan rasa ingin tahu. Sementara itu, Friedberg (1991: 425) mengatakan bahwa keberadaan bioskop di area terpojok dari bangunan mal secara tidak langsung memaksa pengujung untuk melewati, serta diseduksi oleh berbagai lapak dan deretan jendela pajang dari toko-toko yang berada di mal.

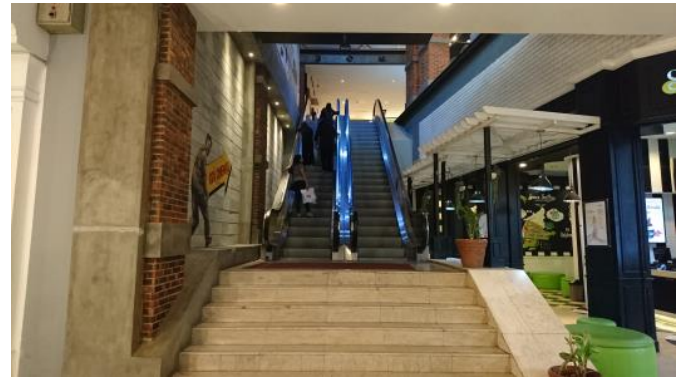

Gambar 4. Bioskop selalu berada di lantai teratas mal.

Sumber: Ageza, 2018.

Selain argumentasi dari kedua pemikir tersebut, berdasarkan observasi lapangan, kami mendapati bahwa keberadaan bioskop yang memberikan kesan terisolir memberikan keuntungan lain yakni bioskop dapat memonopoli berbagai aktivitas yang dilakukan oleh penonton dan calon penonton. Salah satu contohnya adalah toilet khusus untuk penonton bioskop. Meskipun di mal terdapat berbagai fasilitas, serta lapak yang menjual makanan dan minuman, bioskop tetap menyediakan fasilitas mandiri yang diperuntukkan khusus kepada penontonnya. Dengan demikian, bioskop tidak hanya mendapatkan keuntungan dari penjualan tiket film, melainkan juga dari berbagai produk pendamping lain yang ditawarkannya. Sebagai catatan, pihak bioskop memberlakukan harga makanan dan minuman yang cenderung lebih tinggi ketimbang harga rata-rata di tempat lain dengan tujuan untuk menjaga harga tiket bioskop agar tetap terjangkau (Halim, 2017).

Fasilitas yang juga ditonjolkan oleh pihak bioskop adalah teknologi. Teknologi adalah faktor yang membuat bioskop tetap bertahan dari kompetisi dengan televisi (Corbett, 2001) dan internet. Penguasaan terhadap teknologi selalu terkait dengan perkara kapital. Semakin besar kapital yang dimiliki, maka semakin mutakhir pula teknologi yang disediakan. Teknologi menjadi pembeda antarbioskop. Kondisi tersebut menunjukkan pula kompetisi yang didasarkan pada teknologi: semakin mewah dan tinggi kelas sosial dari 
konsumen suatu mal, maka semakin mutakhir teknologi yang dimiliki dan ditawarkannya kepada penonton.

Teknologi yang terdapat di bioskop memberikan keuntungan kepada penonton dan bioskop sendiri. Di satu pihak, penonton diberikan kemudahan. Misalnya, dengan keberadaan mesin tiket, pembeli tidak perlu mengantre panjang pada loket konvensional. Sensor otomatis pada sabun dan keran membuat pengguna lebih higienis, serta berkontribusi pada penghematan air. Di lain pihak, bioskop pun diuntungkan dari teknologi tersebut: meminimalisasi jumlah pekerja di loket tiket konvensional, serta mengurangi biaya penggunaan sabun dan air. Contoh lain dari pemanfaatan teknologi adalah sistem pembelian tiket daring. Bioskop diuntungkan karena pengurangan jumlah antrean pembeli tiket di loket, serta memungkinkan bioskop mendapatkan pembayaran lebih cepat daripada pembelian di loket konvensional. Penguasaan terhadap teknologi memiliki andil terhadap tutupnya bioskop nonjaringan dan bioskop di luar mal di Bandung. Bioskop yang tidak dilengkapi dengan teknologi mutakhir sulit untuk bersaing mendapatkan penonton.

Perkara ruang, fasilitas, dan teknologi kemudian terkait dengan prinsip standarisasi. George Ritzer mengatakan bahwa mal adalah pengejawantahan dari prinsip no-thing (2004). Nothing dalam pemikiran Ritzer berarti "generally centrally conceived and controlled social forms that are comparatively devoid of distinctive substantive content" (2004: xi). Prinsip tersebut membuat mal di berbagai tempat di dunia memiliki keserupaan bentuk, serta diisi oleh merek-merek internasional yang serupa. Dengan kata lain, pada tingkat general hanya terdapat keserupaan, dan tidak terdapat keistimewaan. Mal Paris van Java dan CGV Cinemas adalah contoh dari prinsip tersebut. CGV Cinemas dan toko-toko yang terdapat di mal Paris van Java seperti Zara, H\&M, Stradivarius, dan Mango adalah contoh dari merek-merek global. Terdapat keseragaman dalam aspek keruangan dan produk merek-merek global tersebut. Sebagai perusahaan dengan jangkauan nasional, Cineplex 21 juga menerapkan sistem standarisasi. Prinsip tersebut nampak dari keserupaan tampilan ruangan dan film yang ditawarkan oleh berbagai cabang bioskop Cineplex 21 seIndonesia. Standarisasi memungkinkan mal dan bioskop memperkecil pengeluaran modal, memperbesar keuntungan kapital, menjangkau pasar yang luas, serta mudah diidentifikasi di mana pun keberadaannya.

Prinsip no-thing bekerja secara simultan dengan prinsip some-thing, yakni variasi di tingkat detil. Prinsip something terkait dengan glokalisme (global-lokalisme), yakni manifestasi globalisasi di tingkat lokal. Prinsip some-thing memungkinkan perusahaan multinasional seperti CGV Cinemas menjual produk lokal seperti pisang goreng.

Sebagaimana yang sudah dipaparkan pada subjudul sebelumnya bahwa bioskop Ciwalk XXI dan CGV Cinemas Paris van Java berupaya menghadirkan suasana alam yang asri ke dalam lingkungan bioskop. Friedberg (1991: 424) menjelaskan kondisi ini dengan mengatakan bahwa mal menghadirkan ilusi luar-ruangan (outdoor) untuk membuat pengunjung merasa betah dan nyaman. Sementara itu, Lefebvre menyatakan bahwa kota mencerabut kehidupan keseharian manusia untuk kemudian dikomodifikasi. Bertolak dari kedua pemikiran tersebut, maka keberadaan area hijau pada mal dan bioskop di mal adalah contoh komodifikasi yang diakibatkan oleh perubahan dari ruang hidup manusia: ruang hidup alamiah dan asri berubah menjadi kota.

Dengan mengikuti pendapat Lefebvre (1991: 26) "(social) space is a (social) product”, dapat diargumentasikan bahwa jika ruang adalah kapital dan produk, maka penambahan berbagai fasilitas, teknologi, standarisasi, dan ilusi luar-ruangan pada ruang pada bioskop di mal menunjukkan bagaimana kapital perlu 
selalu direproduksi untuk memaksimalkan keuntungan dan menghasilkan lebih banyak kapital.

\section{Komodifikasi Pengalaman}

Integrasi antara mal dan bioskop tidak hanya sekadar penyatuan ruang yang memungkinkan keduanya bersinergi dan bersimbiosis untuk menarik keuntungan lebih banyak, melainkan juga mengubah cara hidup manusia urban. Bioskop di mal membuat pengalaman berbelanja di mal dan menonton di bioskop berlangsung secara simultan. Dengan demikian, penonton film di bioskop pasti adalah juga konsumen mal.

Kondisi tersebut membawa beberapa konsekuensi logis. Pertama, menonton film di suatu bioskop hanya dapat dilakukan oleh orang dengan kapital yang sesuai dengan segmentasi mal yang dituju: semakin mewah suatu mal, semakin mahal pula biaya tiket menonton. Kedua, warga kota dari kelas bawah tidak lagi memiliki akses ke bioskop. Sebab segmentasi pasar konsumen mal menyasar kelas menengah dan atas. Kondisi ini berbeda jauh dengan era sebelum masuknya bioskop ke mal, yakni ketika bioskop masih berupa bangunan mandiri dan/atau belum terkait dengan jaringan bioskop. Bioskop memiliki rentang harga yang lebih bervariasi (menjangkau berbagai kelas sosial-ekonomi). Ketiga, sebagaimana produk yang tersedia di mal, bioskop hanya akan memutarkan film-film yang laris saja. Sebagai contoh adalah film Dilan 1990 dan Maze Runner yang diputarkan oleh mayoritas bioskop di Bandung, termasuk di CGV Cinemas Paris van Java dan Ciwalk XXI. Terdapat pula anggapan bahwa film yang bagus berarti film yang laku ditonton oleh banyak orang (Nova, 2014). Keempat, karena mal diasosiasikan sebagai tempat hiburan, maka film yang diputarkan bioskop di mal memiliki penekanan pada unsur hiburan. Kelima, film menjadi produk. Oleh karena itu, terjadi pergeseran penekanan makna dari menonton film menjadi mengonsumsi film. Dengan demikian, film di bioskop menjadi sejajar dengan (misalnya) kopi di lapak kedai kopi, baju di toko fashion, dan makanan di restoran cepat saji.

Untuk memaksimalisasi keuntungan, bioskop perlu menjangkau segmentasi pasar yang luas. Oleh sebab itu, bioskop menyediakan variasi vertikal dan horizontal kepada calon penonton. Hal ini berkaitan pula dengan sistem sinepleks yang diterapkan oleh bioskop di mal. Sistem sinepleks membuat variasi ini dimungkinkan. Variasi horizontal yakni berupa variasi genre dan rating usia film. Variasi vertikal yakni berupa variasi kelas atau fasilitas menonton, seperti teknologi layar, suara, dan tempat duduk.

$$
\text { Kontrol adalah prinsip yang }
$$
membentuk kehidupan urban. Mal beroperasi dengan didasarkan pada kontrol. Pertama, mal mengontrol pengalaman pengunjung mal dan/atau penonton film di bioskop agar senantiasa berada dalam koridor pengalaman yang aman, bersih, dan nyaman. Kedua, mal dan bioskop di mal juga mengontrol ruang. Ketiga, mal dan bioskop di mal mengontrol pilihan konsumen. Kontrol atas ruang tercermin dari keberadaan kamera pengawas (CCTV) di area bioskop dan di dalam ruangan menonton (studio/teater/auditorium). Cineplex 21 mengeksplisitkan aspek kontrol tersebut dengan keberadaan pintu kaca, dan petugas keamanan dengan alat detektor logam di Ciwalk XXI. Kontrol atas pilihan tercermin dari pilihan-pilihan film, makanan, dan minuman yang disodorkan kepada calon penonton. Terkait dengan pemaparan sebelumnya bahwa keberadaan bioskop di mal telah menyempitkan posisi penonton pada pengunjung mal, maka bioskop akan cenderung memberikan tawaran film-film yang laris. Film yang cenderung ditawarkan kepada calon penonton adalah film yang menampilkan kisah yang sejalan dengan gaya hidup yang ditawarkan oleh mal, cenderung menggunakan cara pandang atau berorientasi pada kelas menengah dan atas, 
serta berkelindan dengan kehidupan masyarakat urban. Dengan demikian, mal dan bioskop di mal dapat memaksimalkan keuntungan yang diperoleh, sekaligus pula memelihara gaya hidup pengunjung mal dan penonton bioskop.

Pada bagian sebelumnya telah dijelaskan tujuan dari penempatan bioskop di lantai teratas mal. Salah satu tujuannya adalah agar calon penonton terlebih dahulu melewati dan melihat jendela pajang tokotoko sebelum tiba di area bioskop. Layar bioskop analog dengan jendela pajang toko di mal (Friedberg, 1991: 423). Friedberg (1991: 420) menyebutkan istilah consumerspectator (konsumen-penonton) untuk menunjuk pengunjung mal. Layar bioskop dan jendela pajang membingkai, mempertontonkan, dan menjual produk (1991: 423). Berdasarkan penjelasan Friedberg tercermin bahwa pada jendela pajang toko, maneken dan produk ditampilkan secara statis, sementara tubuh pengunjung mal bergerak. Pada layar bioskop terjadi kondisi sebaliknya: adanya gerak dari film dan iklan yang ditayangkan, sementara tubuh penonton dibuat statis.

Berkesesuaian dengan Friedberg, Debord (1970) menyebutkan istilah spectacle of society: segala yang dapat dipertontonkan adalah komoditas, dan komoditas perlu dipertontonkan. Friedberg dan Deborg meradikalkan istilah menonton dengan tidak hanya terbatas pada perkara menonton film. Mengacu kepada kedua pemikiran tersebut, maka kondisi dua arah terjadi di mal. Pertama, pengunjung menonton segala hal yang terdapat di ruang mal, seperti jendela pajang toko, maneken, neon box poster film, film dan iklan di layar bioskop, serta sesama pengunjung. Kedua, pengunjung mal berbelanja produk, ide, dan pengalaman.

Kegiatan menonton film di bioskop mal mengeksplisitkan peristiwa konsumsi atas ide dan pengalaman. Di dalam ruangan menonton (studio/teater/ auditorium), produk yang dibeli penonton adalah ide dan pengalaman yang diputarkan di layar bioskop. Konsumsi atas ide menjadi sesuatu yang tidak terhindarkan sebab ide termaktub di dalam film dan iklan yang ditampilkan pada layar bioskop. Ide tersebut kemudian mengarahkan penonton untuk melakukan konsumsi produk. Sebagai contoh, ide mengenai pelajar SMA yang romantis dan menjadi idola dalam film Dilan 1990 membangkitkan kembali tren jaket jeans (Librianty, 2018).

Sementara itu Friedberg menjelaskan konsumsi atas pengalaman dengan "Shopping-mall cinemas demand an expenditure. They offer the pleasure of purchase, but instead of delivering a tangible product, they supply an experience." (1991: 424). Kembali pada pemikiran Lefebvre (1991) yang dipaparkan pada subjudul sebelumnya bahwa kota urban mencerabut pengalaman hidup keseharian agar dapat dikomodifikasi. Maka, pengalaman yang dihadirkan oleh film menjadi contoh konkret dari pemikiran tersebut.

Keberadaan fasilitas auditorium 4DX pada CGV Cinemas Paris van Java dan area permainan video (videogame) pada Ciwalk XXI menjadi dua contoh dari intensifikasi pengalaman. Paul mengatakan bahwa mesin videogame di bioskop menunjukkan sinergi antara film dan videogame (1994: 497-498). Dalam pemikiran Paul, sinergi tersebut dimungkinkan karena terjadinya perubahan cara menonton, yakni bioskop berupa bangunan mandiri dengan sebuah layar tunggal, kemudian menjadi kompleks sinema (sinepleks) dengan ruangan menonton yang lebih kecil. Perubahan tersebut menunjukkan terjadinya penurunan skala atmosfer dalam menonton film (Paul, 1994: 501). Penurunan skala tontonan tersebut analog dengan kegiatan menonton videogame (Paul, 1994: 498). Di samping pendapat Paul tersebut, berdasarkan observasi kami, sinergi antara videogame dan film dimungkinkan karena keserupaan produk yakni berupa gambar bergerak yang mengintensifikasi 
pengalaman hidup riil, serta simbiosis mutualisme dari adaptasi videogame menjadi film. Tidak hanya fasilitas 4DX, slogan yang terdapat pada mural di dinding CGV Cinemas Paris van Java juga mengisyaratkan pengalaman sebagai komoditas. Mural slogan yang terdapat di CGV Cinemas Paris van Java antara lain "Envolving beyond movies, bring cinema to your life" dan "Where your special movie experience begins".

Dengan demikian, peristiwa menonton film tidak hanya mencerabut pengalaman hidup keseharian, melainkan juga memungkinkan penonton merasakan pengalaman baru dan mengintensifkan pengalaman melalui film-film yang ditontonnya. Namun, berbeda dari pengalaman riil, pengalaman yang didapat melalui menonton film di bioskop adalah pengalaman yang didasarkan pada atmosfer mal, yakni aman, bersih, dan nyaman (Friedberg, 1991: 424), serta tubuh yang statis (karena hanya sebagai penonton). Meskipun film menampilkan adegan genting dan berbahaya, penonton hanya bergeming dengan nyaman di tempat duduk bioskop.

\section{Bioskop di Mal sebagai Miniatur Kota}

Kota berupaya menciptakan suasana kehidupan yang aman dan nyaman bagi warga urban yang jumlahnya tinggi dan heterogen. Sebagai perbandingan, jumlah penduduk desa tidak setinggi di kota, dan warganya cenderung homogen (misalnya dalam hal pekerjaan) (Basundoro, 2012: 18-19). Oleh sebab itu, kota perlu menerapkan sejumlah mekanisme untuk mengatur warga kota, antara lain melalui kontrol dan standarisasi. Selain untuk memperbesar keuntungan (seperti yang sudah dipaparkan pada bagian sebelumnya), standarisasi diberlakukan karena kota tidak mampu mengakomodasi kepentingan/kehendak dari tiap-tiap warga kota yang jumlahnya banyak dan heterogen.
Di saat bersamaan, kota menjadi lokus dari kapitalisme modern. Walter Benjamin sebagaimana dikutip oleh Gilloch mengatakan

"... to the representation of the city as the essential locus of modern capitalism dan its attendant evils of exploitation, injustice, alienation, and the diminution of human experience" (1996: 1).

Mengacu pada kedua kondisi tersebut, maka dapat dikatakan bahwa mekanismemekanisme yang dipergunakan untuk mengatur warga kota, di saat bersamaan digunakan pula untuk mengeruk keuntungan dan mengeksploitasi. Pemikiran Walter Benjamin tersebut berkesesuaian dengan pemikian Lefebvre yang sudah dipaparkan pada bagian sebelumnya.

Ruang terkait dengan pengalaman. Perubahan atas ruang mengubah pula pengalaman hidup manusia. Kapitalisme menguasai dan memprivatisasi ruang kota, akibatnya pengalaman hidup manusia mengalami komodifikasi pula. Mal adalah miniatur dari kota, oleh karena itu cara kerja kota termaktub pula di dalam cara kerja mal. Kota perlu mencerabut pengalaman hidup riil keseharian manusia urban, agar dapat menjualnya kembali dalam bentuk komoditas. Mal menjadi tempat untuk menjajakan komoditas.

Bioskop di mal menunjukkan bagaimana ruang-ruang yang mulanya terpisah disatukan. Penyatuan tersebut bertujuan untuk memperkecil biaya operasional, dan memaksimalkan keuntungan bagi mal dan bioskop. Di satu pihak, ruang (fisik) dimampatkan. Di pihak lain, pengalaman (mental) diperluas dan diintensifkan. Perluasan dan intensifikasi dari kegiatan menonton film di bioskop membuat penonton mengalami pengalaman hidup yang berbeda dari pengalaman hidup riil keseharian yang cenderung monoton, terkontrol, dan terstandar. Mural di dinding CGV 
Cinemas Paris van Java menunjukkan hal tersebut dengan slogan "Fun and unique experience". Singer (2001) menegaskannya dengan menyatakan bahwa kehidupan modern urban yang monoton membuat warga urban membutuhkan tontonan melodrama. Perkataan Singer menunjukkan bahwa manusia urban menjadikan tontonan (dalam hal ini mengacu pada film) sebagai kompensasi atas pengalaman hidup kesehariannya yang sudah tercerabut oleh kota. Pengalaman yang ditawarkan oleh film yang diputar di bioskop mal itu perlu dibayar dengan kapital.

Berdasarkan pembahasan yang sudah dipaparkan, dapat diargumentasikan bahwa kota analog dengan bioskop di mal. Sebagaimana bioskop di mal, kota juga menguasai ruang dengan menawarkan eksplorasi pengalaman dan aneka fasilitas. Pengalaman dan ruang yang ditawarkan oleh kota perlu ditebus dengan sejumlah kapital, mengandaikan adanya kontrol guna menciptakan keamanan dan kenyamanan, tubuh yang diarahkan untuk menjadi statis (agar dapat dikontrol), serta standarisasi kehidupan yang menyebabkan kemonotonan dan pengabaian terhadap keunikan.

\section{PENUTUP}

Semua bioskop di Kota Bandung berada di mal. Sebaliknya, nyaris semua mal di Kota Bandung memiliki bioskop. Fenomena tersebut menunjukkan bahwa telah terjadi sinergi dan simbiosis antara mal dan bioskop. Artikel ini disusun berdasarkan studi kepustakaan dan hasil observasi dari dua bioskop terbesar di Bandung, yakni Ciwalk XXI di Mal Cihampelas Walk, dan CGV Cinemas Paris van Java di Mal Paris van Java.

Penyatuan mal dan bioskop menyebabkan konsekuensi. Penyatuan mal dan bioskop menunjukkan bagaimana kapitalisme dan kota menguasai ruang untuk mereproduksi kapital dan menarik keuntungan. Ruang fisik dimampatkan, sementara keuntungan kapital dimaksimalkan. Komodifikasi ruang kemudian menyebabkan perubahan cara manusia urban dalam mengalami peristiwa berbelanja di mal dan menonton di bioskop. Berbelanja dan menonton menjadi sebuah kesatuan kegiatan yang terjadi secara simultan. Film menjadi produk, dan sejajar dengan produk-produk yang ditawarkan oleh toko/lapak lain di mal. Di mal, kegiatan menonton film mengalami pergeseran penekanan makna menjadi mengonsumsi film. Sebaliknya, pengunjung mal tidak hanya menonton film di bioskop mal, melainkan pula menonton segala sesuatu yang terdapat di mal.

Melalui kegiatan menonton film di bioskop mal, kapitalisme dan kota mengomodifikasi pengalaman. Meski ruang dimampatkan, pengalaman hidup diperluas melalui kegiatan menonton film. Komodifikasi pengalaman diuntungkan pula oleh kondisi kehidupan warga kota yang monoton dan terstandar. Dengan perkataan lain, penyatuan mal dan bioskop bertujuan untuk menghimpun lebih banyak konsumen, memperkecil biaya operasional, serta memaksimalkan keuntungan kapital yang diperoleh.

Kota mencerabut ruang hidup dan pengalaman hidup keseharian warga kota, untuk kemudian dikomodifikasi, dan dijual kembali kepada warga kota. Warga kota perlu menebusnya dengan kapital. Dengan demikian, kota tidak hanya analog dengan mal, melainkan juga dengan bioskop di mal. Sebagaimana mal, bioskop di mal adalah juga miniatur dari kota.

\section{DAFTAR SUMBER}

\section{Jurnal}

Corbett, K. J. 2001.

The Big Picture: Theatrical Moviegoing, Digital Television, and Beyond the Substitution Effect. Cinema Journal, 40(2), 17-34. Retrieved from www.jstor.org/stable/ 1225841.

Friedberg, A. 1991.

Les Flaneurs du Mal(1): Cinema and the Postmodern Condition. PMLA, 106(No. 
3), 419-431. Retrieved from http://www.jstor.org/stable/462776.

Paul, W. 1994.

The K-Mart Audience at the Mall Movies. Film History, 6(4), 487-501.

\section{Buku}

Barker, C. 2014.

Kamus Kajian Budaya. Yogyakarta: Kanisius.

Basundoro, P. 2012.

Pengantar Sejarah Kota. Yogyakarta: Penerbit Ombak.

Buck-morss, S. 1989.

The Dialectics of Seeing: Walter

Benjamin and the Arcades Project. Cambridge: The MIT Press.

Debord, G. 1970.

The Society of the Spectacle. Detroit: Black \& Red.

Friedberg, A. 1993.

Window Shopping: Cinema and the Postmodern. California: University of California Press.

Gilloch, G. 1996.

Myth and Metropolis: Walter Benjamin and the City. Oxford: Polity Press in association with Blackweel Publishers.

Lefebvre, H. 1991.

The Production of Space. Oxford: Basil Blackwell.

Maulana, S. 2002.

Filsafat Komunikasi: Dari Sokrates hingga Buddhisme Zen. Bandung: Publika Edu Media.

Neumann, J. von, \& Morgenstern, O. 2004. Theory of Games and Economic Behaviour (60th ed.). Princeton: Princeton University Press.

Parker, S. 2004

Urban Theory and the Urban

Experience: Encountering the City. London: Routledge.

Ritzer, G. 2004

The Globalization of Nothing.

California: Sage Publications.

Sen, K. 2009.

Kuasa dalam Sinema: Negara, Masyarakat, dan Sinema Orde Baru.
Yogyakarta: Penerbit Ombak.

Singer, B. 2001

Melodrama and Modernity. New York: Columbia University Press.

\section{Internet}

Adi. 2013. Inilah 5 Bioskop Kenangan di Bandung. Diakses dari http://bandung.bisnis.com/read/ 20130822/34242/418379/inilah-5bioskop-kenangan-di-bandung, Tanggal 7 Januari 2018 pukul 12.38 WIB.

Bookmyshow. 2017a.

History of Cinema: CGV Cinemas.

Diakses dari https://.id.bookmyshow.com/ cinemaslist/cgv-blitz/all-regions/cbof, Tanggal 5 Februari 2018 pukul 20.00 WIB.

Bookmyshow. 2017b.

History of Cinema: Cinema XXI.

Diakses dari

https://id.bookmyshow.com/cinemaslist/cinema21/all-regions/21c, Tanggal 5 Februari 2018 pukul 20.13 WIB.

CGVCinemas. 2018a. CGV Cinemas. Diakses dari https://www.cgv.id, Tanggal 10 April 2018 pukul 22.15 WIB

CGVCinemas. 2018b.

Schedule CGV Cinemas Paris van Java. Diakses dari https://www.cgv.id/en/schedule/cinema/ 001, Tanggal 5 Februari 2018 pukul 21.30 WIB.

Cineplex21. 2018a

Cineplex 21. Diakses dari https://21cineplex.com, Tanggal 10 April 2018 pukul 22.20 WIB.

Cineplex21. 2018.

Cineplex 21: About Us. Diakses dari https://21cineplex.com/ gui.about.php, Tanggal 7 Mei 2018 pukul 20.23 WIB

Halim, A. 2017.

Ini Alasan Harga Pop Corn dan Minuman Jauh Lebih Mahal

Ketimbang Harga Tiket di Bioskop. Diakses dari http://tipstren.pojoksatu.id/hiburan/18/1 1/2017/ini-alasan-harga-pop-corn-danminuman-jauh-lebih-mahal-ketimbangharga-tiket-di-bioskop/, Tanggal 5 April 
2018 pukul 19.07 WIB.

Kompas. 2016.

Singapura Jadi Pemegang Sebagian

Saham Cinema XXI. Diakses dari

https://ekonomi.

kompas.com/read/2016/12/06/07554562

6/singapura.jadi.pemegang.sebagian.sah

am.cinema.xxi, Tanggal 5 Februari 2018

pukul 18.45 WIB.

Librianty, A. 2018.

Jaket Dilan Bertebaran di Toko Online.

Diakses dari

https://liputan6.com/tekno/read/3263108/

jaket-dilan-bertebaran-di-toko-online,

Tanggal 10 April 2018 pukul 23.37 WIB.

Maradona, S. 2011.

Regent, Salah Satu Bioskop Tertua di Bandung “Tutup Usia." Diakses dari https://republika.co.id/berita/regional/nu santara/11/09/08/lr7lb7-regent-salahsatu-bioskop-tertua-di-bandung-tutupusia, Tanggal 7 Januari 2018 pukul 00.47 WIB.

Nova, R. 2014.

Keberpihakan Penonton Indonesia. Diakses dari https://cinemapoetica.com/ keberpihakan-penonton-indonesia/, Tanggal 28 Februari 2018 pukul 01.26 WIB.

Wattimena, R. A. A. 2009.

Hermeneutika Hans-Georg Gadamer. Diakses dari https://rumahfilsafat.com/ 2009/09/21/hermeneutika-hans-georggadamer/, Tanggal 6 Mei 2018 pukul 21.45 WIB.

\section{Surat Kabar}

Redana, B. (2016). "Welcome You All". Kompas, 10 Januari 2016. 